\title{
Avaliação e ranqueamento de universidades sob a lógica de critérios globais
}

\author{
Evaluation and ranking of universities on the logic of global criteria
}

\section{Evaluación y ranqueamiento de universidades sobre la lógica de criterios global}

\author{
Raimunda Maria da Cunha Ribeiro ${ }^{1}$ \\ Universidade Estadual do Piauí, Professora no Curso de Pedagogia
}

Resumo: O mundo globalizado tem provocado diversos impactos no contexto universitário, especificamente a necessidade de adequação das instituições aos novos paradigmas impostos pelas mudanças em todos os setores da sociedade. Assim, o objetivo com esta pesquisa implica compreender o processo de avaliação de universidades, a partir de indicadores de ranqueamentos nacional e internacionais, bem como as exigências impostas a essas instituições quanto às mudanças na política de ensino, pesquisa, extensão e gestão. A metodologia adotada foi a abordagem qualitativa, de caráter bibliográfico e descritivo, tendo como elementos os indicadores adotados pelos rankings Ruf, U-Multirank, Quacquarelli Symonds, Ranking Web, THE-TR e Center for World University Rankings no processo de avaliação de universidades. Em linhas gerais, as universidades são submetidas à competitividade; os resultados classificatórios impõem o redirecionamento da política universitária, de forma a remeter a produção do conhecimento para o atendimento de fins, em alta medida, mercantilistas; há uma exagerada corrida das instituições avaliadas para serem reconhecidas como sendo de alta reputação, logo, universidades de classe mundial.

Palavras-chave: Universidade. Avaliação. Ranqueamento.

Abstract: The globalized world has caused several impacts in the university context, specifically, the need to adapt institutions to the new paradigms imposed by changes in all sectors of society. Thus, the objective of this research is to understand the process of evaluation of universities, based on indicators of national and international rankings, as well as the requirements imposed to these institutions regarding changes

1 Doutora em Educação pela Pontifícia Universidade do Rio Grande do Sul; Realizou estágio Pós-Doutoral no Programa de Pós-Graduação em Educação da Universidade do Oeste de Santa Catarina. 
in teaching, research, extension and management policy. The methodology adopted was the qualitative approach, with a bibliographical and descriptive character, using the indicators adopted by the rankings (Ruf, U-Multirank, Quacquarelli Symonds, Web-Ranking, THE-TR, Center for World University Rankings) in the evaluation process of Universities. In general terms, universities are subject to competitiveness; The classificatory results impose the redirection of the university policy, in order to refer the production of the knowledge to the service of ends, to a high degree, mercantilists; There is an exaggerated rush of assessed institutions to be recognized as being of high reputation, thus world-class universities.

Keywords: University. Evaluation. Ranking.

Resumen: El mundo globalizado ha provocado diversos impactos en el contexto universitario, especificamente, la necesidad de adecuación de las instituciones a los nuevos paradigmas impuestos por los cambios en todos los sectores de la sociedad. Así, el objetivo de esta investigación implica comprender el proceso de evaluación de las universidades, a partir de indicadores de rankings nacionales e internacionales, así como las exigencias impuestas a estas instituciones en cuanto a los cambios en la politica de enseñanza, investigación, extensión y gestión. La metodología adoptada fue la abordaje cualitativa, de carácter bibliográfico y descriptivo, teniendo como elementos los indicadores adoptados por los rankings (Ruf, U-Multirank, Quacquarelli Symonds, Ranking Web, THE-TR, Center for World University Rankings) en el proceso de evaluación de Universidades. En líneas generales, las universidades son sometidas a la competitividad; Los resultados clasificatorios imponen el redireccionamiento de la política universitaria, para remitir la producción del conocimiento para la atención de fines, en alta medida, mercantilistas; Hay una exagerada carrera de las instituciones evaluadas para ser reconocidas como de alta reputación, luego, universidades de clase mundial. Palabras clave: Universidad. Evaluación. Clasificación.

\section{INTRODUÇÃO}

Os sistemas de avaliação de universidades têm se ampliado um pouco por todo o globo e, em certa medida, têm reforçado os sistemas de ranqueamentos, tanto em nível nacional quanto em nível internacional. Para compreendermos essa forma de classificação e competitividade entre as instituições precisamos levar em conta as práticas de avaliação e os indicadores desse processo. 
Os sistemas de ranqueamento acabam por colocar em xeque a missão da universidade, uma vez que os novos parâmetros de avaliação da educação superior, associadas ao processo de internacionalização e globalização, têm suscitado alterações no comportamento dessa instituição. As mudanças no ambiente da educação superior tornam-se visíveis, influenciando, inclusive, a missão das universidades. Entre essas mudanças podemos destacar: quebra do monopólio geográfico; e mudanças no modelo organizacional, considerando o modelo global altamente competitivo; crescente interação entre as instituições e o setor produtivo; e larga produção de conhecimento científico, tecnológico e inovador, com a finalidade primeira de promover o desenvolvimento econômico.

Diante desse cenário de mudanças emerge a questão: como podemos analisar a avaliação de instituições de ensino superior e os indicadores condicionantes do processo, de modo que possamos refletir sobre a missão universitária, os fins com que é produzido o conhecimento na universidade e a preocupação das instituições em se tornarem universidades de classe mundial? Assim, o objetivo com esta pesquisa se direciona para o seguinte: compreender o processo de avaliação de universidades, a partir de indicadores de ranqueamentos nacional e internacionais, bem como as exigências impostas a essas instituições quanto às mudanças na política de ensino, pesquisa, extensão e gestão.

A metodologia adotada na pesquisa foi a abordagem qualitativa, de caráter bibliográfico e descritivo, tendo como elementos de análise os indicadores dos rankings Ruf, U-Multirank, Quacquarelli Symonds, Ranking Web, THE-TR e Center for World University Rankings no processo de avaliação de universidades. $\mathrm{O}$ que foi considerado neste estudo, a partir do levantamentos dos rankings, não foi especificamente a classificação das universidades avaliadas, mas, sobretudo, os indicadores ou critérios utilizados por cada ranking, o que nos leva a repensar qual a missão da universidade e qual o valor dado ao conhecimento por ela produzido, assim como qual o lugar da responsabilidade social universitária. O artigo está estruturado de forma a abordar os seguintes aspectos: os rankings e a mudança de paradigma na missão; os rankings e a universidade de classe mundial; e rankings acadêmicos e os indicadores condicionantes. 


\section{OS RANKINGS E A MUDANÇA DE PARADIGMA NA MISSÃo}

A missão social da universidade tende a correr sério risco de ser suplantada por um modelo de educação baseado na economia do conhecimento, amplamente reforçado com o advento da sociedade pós-industrial, em que a produtividade do conhecimento surge como um fator determinante na posição competitiva de uma indústria, de uma empresa e de um país (DRUCKER, 2007). A universidade, por seu turno, tem assumido a posição de uma instituição visivelmente focada na produção do conhecimento e na racionalidade científica. Afonso (2015) nos dá indicativos de que essa instituição, assumindo tal postura, muito tem contribuído para alcançar legitimidade e divulgar o conhecimento e a investigação produzidos, fazendo com esse mesmo conhecimento científico contribua igualmente para legitimar a própria missão da universidade. $\mathrm{O}$ autor ainda argumenta que a legitimidade da universidade em produzir conhecimento também para fins sociais e culturais está posta em causa e, de certa forma, sendo substituída pela legitimidade mercantil, uma vez que o valor do conhecimento é medido mais por critérios quantificáveis, seguindo a lógica da competitividade empresarial.

Não podemos negar que essa lógica empresarial é transportada para o campo da educação superior, emergindo, nesse sentido, a competição institucional tanto entre os pares quanto entre as instituições. Um exemplo, conforme sugere Altbach (2015), é a publicação em periódicos importantes, que tem se tornado o principal critério do sucesso acadêmico no ambiente competitivo do ensino superior.

A visibilidade das universidades quanto à produção e divulgação do conhecimento científico e tecnológico é avaliada por meio dos ranqueamentos que, em sua maioria, adotam a primazia do conhecimento científico e sua sobreposição sobre outras dimensões. A cultura do ranqueamento impulsiona as universidades a implantarem mudanças para, assim, adaptarem a essa lógica ou a esse tipo de indústria (SALMI, 2009), e a incorporarem uma nova missão além do ensino e da pesquisa, ou seja, a missão de promover o desenvolvimento econômico (ETZKOWITZ, 2002). Para tanto, as universidades investem em pesquisas de ponta, principalmente, a partir das parcerias com o setor produtivo, aliadas à filosofia da tecnologia e da inovação.

Os ranqueamentos têm se mostrado cada vez mais presentes, influentes e importantes para a sociedade, como já indicam Altbach, Reisberg e Rumbley (2010). Dessa forma, em conformidade com pesquisas realizadas por Moura e Moura (2013), 
vimos que, com os benefícios proporcionados por uma posição de destaque em sistemas de ranqueamentos, apesar da exagerada competitividade entre instituições e países, as universidades estão aderindo à corrida da reputação, como uma forma de imprimir sua marca em um cenário mundial, logicamente, porque os rankings têm adotado critérios muito mais globais que, propriamente, locais.

Os resultados de rankings universitários podem impactar algumas dimensões, a saber: notoriedade para a instituição, prestígio institucional, expansão e captação de recursos para financiamento de pesquisas; uma boa situação no ranking produz uma imagem favorável no mercado e aumenta a atratividades e os benefícios econômicos; com os rankings, como indutor da qualidade, por meio do estímulo da concorrência, criam-se as condições para o fortalecimento do mercado educacional, na medida em que o consumidor poderá ter elementos referenciais sobre os diversos cursos ofertados pelas universidades, fato que influenciará no momento da escolha (MOURA; MOURA, 2013; DIAS SOBRINHO, 2010; CALDERÓN; POLTRONIERI; BORGES, 2011). Implica, pois, ressaltar que o prestígio das instituições universitárias vem sendo influenciado cada vez mais pela publicação de ranqueamentos nacionais e internacionais (MOURA; MOURA, 2013).

É certo que os rankings, por um lado, podem ser o demonstrativo da alta reputação da instituição, mas, por outro lado, podem servir de parâmetro para a “desqualificação" de instituições no cenário de alta competitividade. Moura e Moura (2013) reconhecem que os ranqueamentos são, geralmente, orientados pelo mercado, utilizando pesos, medidas e indicadores numéricos, e também são capazes de monitorar o desempenho das universidades. Esse cenário impulsiona as instituições a promover mudanças de paradigmas, no sentido de serem reconhecidas como universidades de classe mundial - conceito discutido na seção seguinte.

\section{OS RANKINGS E A UNIVERSIDADE DE CLASSE MUNDIAL}

A análise do papel da educação superior, no contexto de internacionalização, massificação, globalização, mobilidade e utilitarismo do conhecimento, implica, pois, considerá-la a partir de uma perspectiva plural e diversa, mesmo considerando que a lógica do mercado e do setor produtivo influencia sobremaneira a organização e a missão das instituições de ensino superior. 
Apesar de reconhecermos a importância, o lugar e o papel que a universidade tem desempenhado no desenvolvimento das sociedades em suas múltiplas dimensões, críticas têm pesado sobre qual a sua missão em um mundo de rápidas transformações, no qual o conhecimento tem se tornado moeda de alto valor. Severino (2002), em suas considerações sobre o papel difuso da universidade, reconhece que o próprio sentido de sua existência já não parece tão claro e que há um sentimento geral de frustração em relação às expectativas não realizadas e às promessas não cumpridas quanto ao desenvolvimento da própria vida humana. Santos (1997) também reconhece que a universidade duplamente desafiada, pela sociedade e pelo Estado, não parece preparada para defrontar os desafios a ela impostos, os quais demandam adaptação permanente diante de profundas transformações. Eis, então, o porquê de a universidade ter se revelado uma instituição em crise.

A partir de quais indicadores são avaliadas e sob quais critérios são classificadas as universidades? Sabendo que não há uma resposta totalizadora, vimos diante de nossos olhos critérios os mais diversos. Parece a universidade não se incomodar com as exigências dos rankings, levando-nos a considerar que o que mais importa são os resultados e a sua reputação diante dos olhos da sociedade, do Estado e do mercado. Sobre essa questão pesa mais uma crítica, vinda de Santos (1997), ao reconhecer que à medida que a universidade perde sua centralidade, torna-se mais fácil justificar e até impor a avaliação do seu desempenho. Porém, vale aqui ressaltar que a "avaliação não é um empreendimento isento e justificado por si mesmo, não é uma simples aplicação de um método de conferência da produtividade ou da eficiência de uma instituição" (RIBEIRO, 2011, p. 58); “a avaliação é, pois, a ferramenta principal da organização e implementação das reformas educacionais.” (DIAS SOBRINHO, 2010, p. 195).

Podemos dizer que estamos vivendo a era das avaliações, que implica conferir, por parte das instituições e do Estado, um grau de adesão plenamente aceito e naturalizado a respeito desta questão. Longe de ser uma tarefa fácil, a avaliação traz consigo, a um só tempo, desafios e reconhecimento quanto a sua importância. Portanto, conforme assinala Ribeiro (2011), seja qual for o modelo de avaliação ou os critérios adotados, o reconhecimento da necessidade é consensual. Dizemos que a avaliação demanda superação de desafios tal como a própria educação - um processo atravessado por contradições e conflitos, os quais tendem a se acirrar em razão da importância que o conhecimento adquiriu na sociedade da informação, como principal motor da economia, do individualismo e da competitividade (DIAS SOBRINHO, 2010). 
Ao nosso ver, o principal dilema da universidade hoje está em imprimir plenamente sua missão social e educacional, quer dizer, entre produzir conhecimento para fins de desenvolvimento social, cultural e de sustentabilidade, e produzir ciência, tecnologia e inovação para fins de atendimento ao mercado, bem como à cultura do ranqueamento. Essa cultura tende à classificação das instituições em escalas numéricas, traduzidas para o cenário da internacionalização da educação superior em universidades de classe mundial. Pfister e Calderón (2014), em pesquisas realizadas nessa área, concluem que os estudos mais recentes têm remetido à discussão acerca dos rankings para uma esfera global, visto que eles vêm sendo apontados como elementos relacionados à emergência da chamada universidade de classe mundial. Apesar de contestados em função da diversidade de critérios adotados, reconhecemos que os rankings servem de parâmetro de comparação, especialmente em relação aos critérios de excelência internacional, dos quais podemos citar alguns: capacidade da universidade em produzir conhecimento científico e tecnológico em benefício da sociedade; universidade com capacidade empreendedora, independente, em certa medida, da tutela financeira do Estado; capacidade da universidade em produzir inovação em áreas diversificadas do conhecimento; capacidade de mobilidade e internacionalização de seus serviços.

Salmi (2009) destaca que a avaliação da capacidade de iniciativas de excelência das universidades não se configura uma tarefa fácil, pelo menos por duas razões: primeiramente porque a modernização de uma universidade demora muito anos, e outro desafio está relacionado à atribuição, o que requer uma análise em profundidade de estudos de casos. Nessa discussão, Altbach (2003) e Salmi (2009) caracterizam uma universidade de classe mundial como aquela compromissada e aberta ao processo de internacionalização e capaz de adaptar-se a exigências internacionais frente às transformações da sociedade do conhecimento.

A missão social e o compromisso com o desenvolvimento social e cultural tendem a permanecer em segundo plano diante das exigências da avaliação, considerando que os rankings internacionais favorecem claramente universidades de pesquisa (SALMI, 2009; MOURA; MOURA, 2013). Salmi (2009) ainda nos chama a atenção para o fato de que universidades que aderem à corrida da excelência são instituições de renome, muito seletivas e excludentes. A produção do conhecimento (traduzida em reputação) a produção econômica tendem a não ser âmbitos totalmente diferentes, pois um é suscitado e apoiado pelo outro (MAGALHÃES, 2004). 
Assim, na busca pela excelência, as universidades aderem aos valores impostos pela competitividade, para, dessa forma, conseguirem imprimir sua marca e garantir prestígio e reputação no cenário internacional.

Altbach (2003), Salmi (2009) e Vilela (2009) reconhecem que as universidades de classe mundial têm alta reputação e são dotadas de maior capacidade de atrair mais investimentos, fortalecer a capacidade de pesquisa e atrair os melhores professores e alunos; são instituições que perseguem a excelência na pesquisa e no ensino, têm autonomia acadêmica, infraestrutura adequada e corpo docente altamente qualificado. São universidades que voltam seu olhar, sua preocupação e seu foco para o padrão de qualidade internacional, além de cultivar uma cultura acadêmica marcada pelo cosmopolitismo; estão abertas à presença de pessoas de diferentes culturas e entendem a necessidade de uma governança favorável, pautada na autonomia de gestão e liberdade para mudar e, assim, ter a possibilidade de trilhar o caminho que favorece o reconhecimento internacional.

A proposta de um novo paradigma de ensino superior é sempre um desafio para a universidade, e nele devem estar claramente definidos os objetivos, as metas, os valores, a responsabilidade social, os critérios da qualidade e as formas de acesso. Isso implica, pois, a universidade atentar para sua missão e ser capaz de conciliar a sua função científica e a sua função social.

$\mathrm{Na}$ próxima seção serão apresentados os critérios ou indicadores da avaliação adotados pelos rankings contemplados neste estudo.

\section{RANKINGS ACADÊMICOS E OS INDICADORES CONDICIONANTES}

Os rankings acadêmicos permitem, entre outros atributos, comparar instituições, levando em consideração critérios ou indicadores os mais diversos, o que nos leva a considerar que os resultados podem permitir o retrato das instituições, mas não precisamente sua realidade por completo. Já que cada ranking utiliza critérios que lhes são próprios, é necessário entendermos a importância e o peso desses critérios.

O Quadro 1 é um demonstrativo dos critérios utilizados nas avaliações de universidades. Não levamos em consideração os resultados dos rankings, mas os indicadores e a frequência com que aparecem no contexto das metodologias de avaliação. Os critérios analisados são indicadores globais utilizados pelos seguintes 
rankings: Ruf, U-Multirank, Quacquarelli Symonds, Ranking Web, THE-TR e Center for World University Rankings.

Quadro 1 - Rankings acadêmicos e respectivos indicadores condicionantes no processo de avaliação de instituições de ensino superior

\begin{tabular}{|c|c|c|c|c|c|}
\hline Rankings & \multicolumn{5}{|c|}{ Critérios/indicadores } \\
\hline $\mathrm{RUF}^{1}$ & Pesquisa & Inovação & $\begin{array}{l}\text { Internacionali- } \\
\text { zação }\end{array}$ & Ensino & Mercado \\
\hline $\begin{array}{l}\text { U-Multi- } \\
\text { rank }^{2}\end{array}$ & $\begin{array}{l}\text { Investiga- } \\
\text { ção }\end{array}$ & $\begin{array}{l}\text { Transferên- } \\
\text { cia de conhe- } \\
\text { cimento }\end{array}$ & $\begin{array}{l}\text { Ensino e } \\
\text { aprendizagem }\end{array}$ & $\begin{array}{l}\text { Orientação } \\
\text { internacional }\end{array}$ & $\begin{array}{l}\text { Desenvol- } \\
\text { vimento } \\
\text { regional }\end{array}$ \\
\hline $\begin{array}{l}\text { Quac- } \\
\text { quarelli } \\
\text { Symonds } \\
(\mathrm{QS})^{3}\end{array}$ & $\begin{array}{l}\text { Reputação } \\
\text { acadêmica } \\
\text { e entre em- } \\
\text { pregadores }\end{array}$ & $\begin{array}{l}\text { Proporção } \\
\text { professor- } \\
\text {-aluno }\end{array}$ & Publicações & $\begin{array}{l}\text { Número de } \\
\text { doutores }\end{array}$ & $\begin{array}{l}\text { Impacto na } \\
\text { internet }\end{array}$ \\
\hline $\begin{array}{l}\text { Ranking } \\
\text { Web/ We- } \\
\text { bometrics }\end{array}$ & Presença & Impacto & Abertura & Excelência & \\
\hline THE-TR $^{5}$ & Ensino & Pesquisa & Citações & $\begin{array}{l}\text { Desenvolvi- } \\
\text { mento/ } \\
\text { Inovação }\end{array}$ & $\begin{array}{l}\text { Internaciona- } \\
\text { lização }\end{array}$ \\
\hline $\begin{array}{l}\text { Center } \\
\text { for World } \\
\text { University } \\
\text { Rankingss }^{6}\end{array}$ & $\begin{array}{l}\text { Qualidade } \\
\text { do ensino } \\
\text { e do corpo } \\
\text { acadêmico }\end{array}$ & $\begin{array}{l}\text { Empregabili- } \\
\text { dade }\end{array}$ & Publicações & $\begin{array}{l}\text { Influência na } \\
\text { mídia }\end{array}$ & $\begin{array}{l}\text { Citações de } \\
\text { pesquisas e } \\
\text { patentes }\end{array}$ \\
\hline
\end{tabular}

Fonte: os autores.

Notas: ${ }^{1}$ O RUF (Ranking Universitário Folha) é uma avaliação anual do ensino superior do Brasil feita pela Folha desde 2012.

${ }^{2}$ U-Multirank, financiado pela Comissão Europeia, é uma classificação mundial e pluridimensional das universidades.

${ }^{3}$ A QS Quacquareli Symonds (Ranking universitário mundial) foi fundada em 1999 e se estabeleceu como principal fornecedor global de informações sobre educação superior.

${ }^{4}$ Seus objetivos principais são promover a publicação na Web e apoiar iniciativas de acesso eletrônico e publicações científicas; indicadores web são úteis para compreender o desempenho global e visibilidade das universidades.

${ }^{5}$ THE-TR, fundado em 2004, fornece lista das melhores universidades do mundo, avaliadas por meio de ensino, pesquisa, perspectivas internacionais e reputação.

${ }^{6}$ Center for World University Rankings (Centro de Classificações Universitárias Mundiais (CWUR): publica ranking universitário global que mede a qualidade da educação e da formação dos estudantes, bem como o prestígio dos membros do corpo docente e a qualidade da sua investigação. 
Os dados do Quadro 1 nos possibilitam visualizar o peso dos critérios adotados nas avaliações, o que permite aos rankings, a partir dos resultados, classificar as universidades na categoria da alta reputação, logo, na categoria de universidade de classe mundial. O mundo vive a era do conhecimento, das novas tecnologias e dos avanços científicos, e, em decorrência de um cenário em mudanças, países veem na universidade a possibilidade de estarem incluídos no circuito mundial de conhecimento e de competências. Percebemos que o peso da categoria relacionada à pesquisa é quase unânime entre os rankings, de forma a considerarmos que a produção de conhecimento científico e tecnológico é a principal declaração da missão das universidades neste tempo. A preocupação com a produção do conhecimento ocorre pelo fato de ser este, conforme argumento Severino (2002), elemento específico fundamental na construção do destino da humanidade. Daí a importância da educação superior, um processo mediante o qual o conhecimento se produz, se reproduz, se conserva, se sistematiza, se organiza, se transmite e se universaliza. A pesquisa é relevante social e economicamente, ao tempo em que desempenha um papel de continuada vigilância sobre as consequências da aplicação do conhecimento na transformação da realidade física e social, não se reduzindo, portanto, a sua definição a partir da relevância econômica (MAGALHÃES, 2004). Altbach (2015), na arena deste debate, sinaliza que a pesquisa é a principal missão das universidades e que o que é fundamental para os rankings é a concretização de um status global elevado, como é o caso das universidades de classe mundial. O autor argumenta, ainda, que a produtividade da pesquisa é mais fácil de ser avaliada que outros tipos de atividades acadêmicas, como o ensino e a extensão. $\mathrm{O}$ ensino tem sido mencionado e considerado, assim como o envolvimento com a comunidade e as conexões da universidade com o setor produtivo, de igual modo, difíceis de definir e quantificar. Essa é uma das razões pela qual a pesquisa tem se configurado como o padrão das avaliações das universidades, principalmente se são avaliadas para fins de ranqueamento (MAGALHÃES, 2004).

O ensino de excelência aparece como um dos indicadores mais identificados nos rankings analisados, ao lado da pesquisa, uma vez que a universidade é local de formação acadêmica e profissional. O sentido da excelência está na possibilidade de uma formação geral, para além de uma especificidade, assim como o desenvolvimento de competências e habilidades, com vistas à formação profissional com autonomia e capacidade de intervir e contribuir com sua área e com a sociedade como um todo. $\mathrm{O}$ fato de o ensino superior aparecer como central na formação de profissionais 
exige das universidades uma reorganização de suas funções básicas, assim como a declaração de sua missão, para, assim, atender às demandas mais urgentes de seu tempo. Isso implica que o preço da importância do ensino superior é, em grande parte, traduzida pela contratualização, por uma prestação de contas mais apertada e por uma pressão mais forte do lado da eficácia e da eficiência. Significa dizer, dessa forma, que a necessidade de melhor qualificação dos recursos humanos é um requisito da economia e uma aspiração da população que acredita que as pessoas mais educadas (no sentido de quem mais estudou) conseguem melhores empregos e melhores rendas. O relevo legítimo dado à formação de pessoas com competência para circular no mercado de empregos da sociedade e da economia do conhecimento não pode querer dizer a redução da educação superior a projetos de formação unicamente para a empregabilidade (LESSARD, 2006; SCHWARTZMAN; CASTRO, 2013; MAGALHÃES, 2011).

Vale ressaltar que o ensino é uma prática social orientada por objetivos e conhecimentos atrelados aos heterogêneos contextos político, histórico, social e cultural. Na teia dessa discussão, lembramos que o conhecimento tem adquirido particular relevância na conjuntura econômica. Presenciamos o mercado de trabalho exigir pessoas capacitadas, com conhecimento acerca de outros idiomas e mais sensibilidade e tolerância às diferentes culturas existentes no mundo. Tendo em vista que as universidades "são responsáveis pela qualificação e capacitação de um grande número de profissionais [...] são, em consequência, afetadas pelo processo de globalização e precisam responder às novas exigências que lhes são colocadas." (DUARTE; LIMA JÚNIOR; BATISTA, 2007, p. 160).

O impacto da universidade na sociedade, a internacionalização de suas atividades básicas, a orientação para o mercado, a inovação, a qualificação do corpo docente e o número de publicações formam um conjunto de outros indicadores recorrentes nas avaliações aplicadas pelas agências de ranqueamento presentes neste estudo. Esses indicadores estão, de certa forma, relacionados ao conhecimento científico e técnico, que possibilita à universidade aderir a processos de afirmação comparativa e competitiva e que permite a sua apropriação dentro de uma racionalidade crescentemente mercantilista e lucrativa, por meio de estratégias de articulação das universidades com as empresas, em que são fundamentais a inovação, o registro e venda de patentes e outras formas de comercialização de ideias, além de benefícios 
financeiros decorrentes da reserva de propriedade intelectual ou qualquer outra oferta de serviços especializados (AFONSO, 2015).

No contexto dessa discussão, há que considerar um fenômeno crescente denominado internacionalização da educação superior. Hans de Wit (2013), professor na Universidade de Ciências Aplicadas de Amsterdã, dá indicativos que se trata de um processo iniciado há pouco mais de duas décadas. O seu entendimento passa pela compreensão de alguns fatores, como o autor enumera: o desenvolvimento posterior à globalização, a intensificação do tratamento do ensino como commodity e a noção de uma economia e de uma sociedade global do conhecimento. São fatores que interferem nas relações entre os países e, em decorrência, observamos o lugar e o papel das universidades dentre e entre eles.

Advêm desse cenário a competitiva lógica classificatória das universidades e a corrida dessas instituições para estarem colocadas entre as melhores do mundo, ou seja, as universidades de classe mundial. Assim, argumentam Duarte, Lima Júnior e Batista (2007, p. 160), que "o contexto internacional tem exercido pressões sobre as universidades, na medida em há necessidade crescente de que realizem esforços para responderem às demandas impostas por [...] maior interação cultural, econômica e política."

As universidades são organizações complexas e, ao tempo em que têm a capacidade de desempenhar múltiplas tarefas (ensino, pesquisa e extensão), são permeadas de lutas e contradições e exercem papel fundamental no progresso da ciência, na formação profissional e no desenvolvimento da humanidade. Da mesma forma que exercem influência na sociedade, também sofrem influências do campo social, político e econômico. Os rankings são um exemplo de influência na mudança de paradigma das universidades, pois os resultados positivos advindos do processo de avaliação proporcionam a essas instituições reputação e prestígio social e acadêmico e, ainda, a tão almejada classificação como universidade de classe mundial. Implica dizer que "com os benefícios proporcionados por uma posição de destaque em sistemas de ranqueamentos, globalmente, as universidades estão aderindo à corrida por reputação.” (MOURA; MOURA, 2013, p. 217).

Vale considerar que as avaliações das universidades para fins de ranqueamento acabam por implantar de forma sutil, e cada vez mais naturalizada, outro fenômeno em relação à educação superior: a cultura da regulação. Nesse sentido, Moura e Moura (2013) afirmam que a presença dos sistemas de ranqueamentos nacionais e internacionais tem transformado o sistema de produção de parâmetros 
avaliativos das universidades e os critérios de classificação de reputação universitária. E também, vamos considerar, com base em estudos de Afonso (2009), que a avaliação pode ser utilizada como condição fundamental para o desenvolvimento de processos de prestação de contas e de responsabilização, o que nos permite afirmar que essa finalidade da avaliação está presente nos propósitos da cultura de ranqueamento, comprometendo, de certa forma, a autonomia das instituições.

Os indicadores utilizados pelos rankings, demonstrados no Quadro 1, são considerados indicadores de prestígio científico, de crédito simbólico e de capital cultural (BOURDIEU, 1983). O que está em jogo, nessa perspectiva de domínio do campo científico, é a busca de prestígio social obtida através do reconhecimento, em especial, das universidades de classe mundial, além da disputa por posições no campo, o que provoca, sobremaneira, a alta competitividade entre as instituições. A posição de destaque, que Bourdieu chama de posição dominante, é obtida com a posse de alto índice de capital científico e do conhecimento sobre o funcionamento das regras estabelecidas no próprio campo (exemplo: os rankings).

O domínio das regras, no âmbito da cultura de ranqueamento, está na capacidade das universidades em reconhecer as metodologias, os instrumentos e os indicadores utilizados pelos agentes avaliadores. Bourdieu (2004) dá indicativos de que é essa capacidade de entender, internalizar e seguir as regras de funcionamento do campo (aqui, as regras de funcionamento das avaliações aplicadas pelos rankings) que permite ao agente (as universidades) acumular cada vez mais capital científico e, a partir disso, atrair para si prestígio e reconhecimento. Os indicadores utilizados pelos rankings têm nos permitido perceber que as universidades avaliadas tendem a se comportar de forma a acumular capital científico, com o propósito de serem reconhecidas entre os pares concorrentes. Vale lembrar que é a estrutura das avaliações adotadas pelos rankings quem determina, em alta medida, o que os agentes avaliados (universidades) podem e o que não convém fazer, que significa dizer que as instituições tendem a se adequar, com mais precisão, às exigências dos processos de avaliação institucional em nível internacional.

O capital científico é uma "espécie particular de capital simbólico [...], que consiste no reconhecimento (ou no crédito) atribuído pelo conjunto de pares concorrentes no interior do campo científico." (BOURDIEU, 2004, p. 26). O reconhecimento das competências científicas e investigativas das instituições avaliadas permite a elas conquistar autoridade, além de contribuir para diferentes acúmulos 
dentro do campo científico, possibilitando, inclusive, o aumento de seu capital econômico. Consideramos, entretanto, que o aumento do capital econômico obtido com base nos resultados positivos das instituições nos ranqueamentos proporciona a elas outros atributos, como, por exemplo: notoriedade acadêmica, prestígio institucional, expansão e mobilidade, atração pelo melhores alunos, melhores professores e melhores pesquisadores e, ainda, capacidade empreendedora de captação de recursos financeiros (MOURA; MOURA, 2013). Tal reconhecimento é largamente utilizado pelas universidades para atrair agências de fomento à pesquisa, firmar parcerias com o setor produtivo, buscar a confiança do mercado para a empregabilidade de seus egressos e a captação de recursos de órgãos governamentais para financiamento de sua política universitária, com destaque para a produção de ciência.

Sob o domínio do sistema capitalista, não podemos negar o lugar do conhecimento enquanto capital, tanto para as universidades quanto para a sociedade e, principalmente, por ser este considerado o motor do desenvolvimento e do progresso da humanidade. Nessa direção, vale a pena refletir e questionar sobre onde o conhecimento que gera o capitalismo acadêmico é apropriado e explorado pelas universidades e seus investigadores, e em benefício de quem (COLADO, 2003). Os rankings, como nos mostra o Quadro 1, vêm cumprindo um papel cada vez mais visível na classificação de desempenho institucional, tendo como principal indicador a excelência da pesquisa científica e, pelo reducionismo dos indicadores utilizados, têm sido muito contestados (AFONSO, 2015).

Enfim, o que está em jogo neste debate nos parece ser o controle, a apropriação e a distribuição do conhecimento pelas universidades e a alta competitividade a que se impõem para obterem êxito e reconhecimento no âmbito da competência global. Sentimos necessidade de pensar outras alternativas quando a produção e a inovação científica e técnica se enredam fortemente na lógica do capitalismo e, sobretudo, quando a universidade não tem capacidade ou não quer resistir às demandas mais nefastas da economia baseada no conhecimento mercadorizável (COLADO, 2003; AFONSO, 2015). Em muitos casos, as exigências impostas pelos indicadores dos rankings estão em descompasso com as finalidades das universidades em relação ao que pretendem promover em termos de desenvolvimento em nível local ou regional, mas a corrida pela excelência acaba por gerar uma política universitária sintonizada com uma agenda global e capitalista. 


\section{CONSIDERAÇÕES FINAIS}

Com este estudo teve-se como objetivo primeiro compreender o processo de avaliação de universidades, a partir de indicadores de ranqueamentos nacional e internacionais e as exigências impostas a essas instituições quanto às mudanças na política de ensino, pesquisa, extensão e gestão. Para compreender esse processo, propomo-nos analisar o cenário de mudanças da sociedade globalizada e seus reflexos, assim como a necessidade da universidade em adequar-se, no sentido de atender às demandas externas.

O imperativo da cultura de ranqueamento, por sua vez, tem imprimido sua marca nas universidades, e as mudanças de paradigma institucional, às quais nos referimos, dizem respeito às altas exigências quanto ao desempenho acadêmico. Os dados advindos deste estudo nos mostram que a pesquisa e o ensino são os indicadores que mais têm causado impacto no processo de avaliação. Em decorrência dessa cultura, podemos destacar alguns pontos: as universidades são submetidas a uma exagerada competitividade e à busca por resultados e produtividade; os resultados classificatórios impõem o redirecionamento da política universitária, de forma definir a produção do conhecimento para o atendimento de fins mercantilistas; há uma agressiva corrida das instituições avaliadas para serem reconhecidas como de alta reputação, logo, universidades de classe mundial.

A cultura de ranqueamento tem, ainda, tornado-se uma cultura empreendedora, individualista, competitiva e objetiva, tendo como fatores decisivos a excelência acadêmica, a produção do conhecimento científico, tecnológico e inovador e a formação de profissionais para a atender à lógica do mercado, lembrando que tais fatores têm se traduzido em indicadores utilizados pela maioria dos rankings.

O retrato do cenário mundial de mudanças nos leva a crer que as políticas de redirecionamento do paradigma da educação superior, um pouco por todo o globo, ainda que específicas em conformação com as realidades locais, comungam com os imperativos da lógica do mercado, da competitividade, do reconhecimento e do prestígio institucional.

Outra questão que nos chama a atenção é que as universidades, quando avaliadas numa perspectiva de ranqueamento em contexto mundial, passam a valorizar pragmaticamente sua produção intelectual, uma vez que os rankings analisados a partir dos indicadores por eles adotados nos mostram a pesquisa 
como sendo o principal condicionante da avaliação das instituições. A produção e socialização do conhecimento sempre foi e continua a ser a principal atividade da universidade, ao lado do ensino e da extensão. Não questionamos o fato da supervalorização do conhecimento, já que este tem sido, ao longo da história, a ferramenta mais apropriada para o progresso da humanidade. Questionamos, porém, a supervalorização mercantilista que as universidades e outras organizações têm dado ao conhecimento, por vezes, com fins de atender unicamente aos valores e à lógica do mercado. Reconhecemos, entretanto, que o desenvolvimento dos povos advém do conhecimento que, via de regra, é produzido na universidade. A responsabilidade social da universidade reside na produção do conhecimento para a promoção do desenvolvimento em suas múltiplas dimensões: social, cultural, de sustentabilidade e econômico, não reduzindo, porém, ao desenvolvimento e crescimento econômico.

\section{REFERÊNCIAS}

AFONSO, A. J. A educação superior na economia do conhecimento, a subalternização das ciências sociais e humanas e a formação de professores. Avaliação, Campinas; Sorocaba, v. 20, n. 2, p. 269-291, jul. 2015.

AFONSO, A. J. Nem tudo o que conta em educação é mensurável ou comparável: crítica à accountability baseada em testes estandardizados e rankings escolares.

Revista Lusófona de Educação, 13, p. 13- 29, jun. 2009.

ALTBACH, G. P. O que conta para a produtividade nas universidades de pesquisa? Ensino Superior Unicamp, 27 maio 2015. Disponível em: <https://www.revistaensinosuperior.gr.unicamp.br>. Acesso em: 27 mar. 2015.

ALTBACH, G. P. The costs and benefits of world-class universities. International Higher Education, i. 33, p. 5-8, 2003. Disponível em: <https://ejournals.bc.edu/ojs/ index.php/ihe/issue/view/761>. Acesso em: 27 mar. 2017.

ALTBACH, G. P.; REISBERG, L.; RUMBLEY, L. Trends in global higher education: Tracking an academic revolution. Boston: Sense Publications, 2010.

BOURDIEU, P. O campo científico. In: ORTIZ, R. (Org.). Bourdieu. São Paulo: Ática, 1983. p. 82-121.

BOURDIEU, P. Os usos sociais da ciência: por uma sociologia clínica do campo científico. São Paulo: UNESP, 2004. 
CALDERÓN, A. I.; POLTRONIERI, H.; BORGES, R. M. Os rankings rankings na educação superior brasileira: políticas de governo ou de Estado? Ensaio: Avaliação Políticas Públicas. Educ., Rio de Janeiro, v. 19, n. 73, p. 813-826, out./dez. 2011.

COLADO, E. I. Capitalismo académico e globalización. Educação e Sociedade, Campinas, v. 24, n. 84, p. 1059-1067, set. 2003. Disponível em: <www.cedes.unicampi.br>. Acesso em: 01 abr. 2017.

DIAS SOBRINHO, J. Avaliação e transformações da educação superior brasileira (1995-2009): do Provão ao Sinaes. Avaliação, Campinas, v. 15, n. 1, p. 195-224, 2010 .

DRUCKER, P. Sociedade pós-capitalista. Lisboa: Actual, 2007.

DUARTE, R. G.; LIMA JÚNIOR, A. F. de; BATISTA, R. V. L. O processo de internacionalização das instituições de ensino superior: o caso das Pontifícias Universidades Católicas de Minas Gerais e do Paraná. E\&G Economia e Gestão, Belo Horizonte, v. 7, n. 14, p. 1-178, 1, 2007.

ETZKOWITZ, H. MIT and the rise of entrepreneurial science. New York: Routledge, 2002.

HANS DE WIT. Repensando o conceito da internacionalização. Ensino Superior Unicamp, International Higher Ecucation, 20 fev. 2013. Disponível em: <https:// www.revistaensinosuperior.gr.unicamp.br>. Acesso em: 31 mar. 2017.

LESSARD, C. A universidade e a formação profissional de docentes: novos questionamentos. Educação e Sociedade, Campinas, v. 27, n. 94, p. 201-227, jan./abr. 2006. Disponível em: <www.cedes.unicamp.br>. Acesso em: 31 mar. 2017.

MOURA, B. A.; MOURA, L. B. A. Ranqueamento de universidades: reflexões acerca da construção de reconhecimento institucional. Acta Scientiarum, Education Maringá, v. 35, i. 2, p. 213-222, July/Dec. 2013.

MAGALHÃES, A. A identidade do ensino superior: política, conhecimento e educação numa época de transição. Porto: Fundação Calouste Gulbenkian; Fundação para a Ciência e Tecnologia, 2004.

MAGALHÃES, A. Cenários, dilemas e caminhos da educação superior europeia. Perspectiva, Florianópolis, v. 29, n. 2, p. 623-647, jul./dez. 2011.

PFISTER, M.; CALDERÓN, A. I. Os rankings na educação superior brasileira: um estudo sobre o estado da questão. Encontro de Iniciação Científica, 19; Encontro de Iniciação em Desenvolvimento Tecnológico e Inovação, 9. Anais... 23-24 set. 2014. 
RIBEIRO, J. L. L. de S. Avaliação das universidades brasileiras: as possibilidades de avaliar e as dificuldades de ser avaliado. Avaliação, Campinas; Sorocaba, v. 16, n. 1, p. 57-71, mar. 2011.

SALMI, J. The challenge of establishing world-class universities. Washington: The World Bank, 2009.

SANTOS, B. S. Pela mão de Alice: o social e o político na pós-modernidade. São Paulo: Cortez, 1997.

SCHWARTZMAN, S.; CASTRO, C. de M. Ensino, formação profissional e a questão da mão de obra. Ensaio: aval. pol. públ. Educ., Rio de Janeiro, v. 21, n. 80, p. 563-624, jul./set. 2013.

SEVERINO, A. J. Educação e universidade: conhecimento e construção da cidadania. Interface. Comunicação, Saúde, Educação, v. 6, n. 10, p. 117-124, fev. 2002.

VILELA, S. USP: uma universidade de classe mundial. In: VILELA, Sueli; FRANCO, Maria Lajolo (Org.). USP 2034: Planejando o Futuro. São Paulo: EDUSP, 2009.

Recebido em: 08 de agosto de 2017 Aceito em: 11 de dezembro de 2017

Endereço para correspondência: Rua Desembargador Amaral, 1584, 64980-000, Corrente, Piauí, Brasil; raicribeiro@ig.com.br 